\title{
Nestedness in bipartite networks of Thuja plicata, Prunus laurocerasus and Buxus sempervirens and their pathogens
}

\author{
E. Fodor, O. Hâruța
}

Fodor E., Hâruta O., 2014. Nestedness in bipartite networks of Thuja plicata, Prunus laurocerasus and Buxus sempervirens and their pathogens. Ann. For. Res. 57(1): 71-86, 2014.

Abstract. The trade with cultivated plants is one of the major pathways for the introduction of invasive species, pathogens included. Based on network analysis, the present study aimed the interaction between several species of cultivated woody perennials found in gardening outlets and nurseries trading with ornamental species and their documented pathogens. Focal species of the host list were Thuja plicata, Buxus sempervirens and Prunus laurocerasus, the selection being based on reported bestselling figures. Bipartite, qualitative, undirected networks were constructed to incorporate woody perennials as hosts and their documented pathogens. The tested network properties were: connectance, node degree distribution, web asymmetry and nestedness. Cluster analysis using Euclidian distance and niche overlap index of Pianka were employed as additional pattern description metrics. The main network containing 33 host species and 112 pathogens was characterized by truncated power law distribution fitting the observed degree distribution of hosts and power law distribution fitting the observed degree distribution of pathogens, low connectance $(C=0.12)$, intermediate web asymmetry $(W=0.54)$ and high significant nestedness $(N=0.94)$. The network containing three focal hosts showed significant lower nestedness $(N=0.54)$, higher asymmetry $(W=0.94)$ and higher connectance $(C=0.38)$. Cluster analysis revealed the separation of focal species distinctly, the majority of other hosts merging in one cluster. Due to the prevalence of specialized pathogens the niche breadth was narrow, with small overlap in resources' partition (Pianka index $=0.31$ ). Our results showed that a random assembly of hosts (woody ornamentals displayed for sale in retail centers and nurseries) could harbor pathogens which attached in a non-random manner, generating a characteristic pathosystem, with distinctive topology. The possible implications of the study consisted in a new insight in invasive spread and the inclusion of new pathogens in local pathogen communities using network analysis as a powerful investigation tool. Keywords bipartite network, invasive species, pathogens, Thuja plicata, Buxus sempervirens, Prunus laurocerasus 
Authors. Ecaterina Fodor (ecaterina.fodor@gmail.com), Ovidiu Hâruța - Forestry Department, Faculty of Environmental Protection, University of Oradea, Romania.

Manuscript received February 07, 2014; revised April 15, 2014; accepted April 22, 2014; online first April 30, 2014.

\section{Introduction}

Invasive and emerging pathogens are major threats to biodiversity of wild as well as cultivated plant species and larger scale, to animals, humans included. Many pathogens escaped from cultivated ornamental into the wild influencing the decline of several forest woody species (Santini et al. 2013). On the other hand, the invasion of thousands of new species from viruses to mammals opened the opportunity to large scale ecological experiments, theory testing and predictions within the new subdomain of invasion ecology (Keller et al. 2011).

Cultivated ornamentals or nursery propagated wild species mediated through trade the introduction of dangerous pathogens all over the world. Dramatic examples in Europe were related to the introduction of Phytophthora ramorum Werres, De Cock \& Mann in't Veld, Phytophthora cinnamomi Rands, Cryphonectria parasitica (Murr.) Barr, Ophiostoma ulmi (Buism.) Nannf. and Ophiostoma novo-ulmi Brasier, Sphaeropsis sapinea Dyco \& Sutton among many other species of alien and invasive pathogens (La Porta et al. 2008).

Generally, pathogens are studied in pairwise combinations, one pathogen and one host at a time but, pathogens exist in the larger context of food webs (Lafferty et al. 2006) and the host - pathogen interaction is continuously exposed to abiotic and biotic environment (Borer 2013). The study of plant-pathogen interaction took benefit during the last years of new analytical approaches such as graph theory. Graphs are flexible conceptual models which can elucidate the relationship between structure and function in ecological systems (Dale \& Fortin 2010). The networks depicting the relation- ships among target organisms (in the present case among plant hosts and their pathogens) present properties which can be quantified by descriptors of the ecological interaction (Poulin 2010). Network analysis sheds light on the structure and dynamics of communities, on community assembly mechanisms and ultimately, ecosystem functioning. Their topology is non-random and specific for the relationship type involved. Currently, the parasitic interactions are depicted by bipartite networks, with links between two groups of species, generally between two trophic levels but not within each group (Williams 2011). Among most important metrics analyzed in bipartite networks is nestedness defined as the number of interactions linking species in a dynamic community (Thompson 1994), previously used to characterize species distributions. Lately, it was used to analyze interaction networks (Bascompte et al. 2003, Guimarães et al. 2006, AlmeidaNeto et al. 2007). The concept has been first defined in the frame of biogeography: small communities are forming proper subsets of larger communities (Atmar \& Patterson 1993). It is an ecological pattern reported for species assemblages in communities and metacommunities and in species interactions (Burns 2007) considered to be widespread in nature (Almeida-Neto et al. 2007). Nested patterns were reported for antagonistic and mutualistic networks (Bascompte et al. 2003, Guimarães et al. 2006, Poulin 1997, Vásquez et al. 2005) for consumer guilds associated with particular resources such as insects inhabiting and feeding on fungal sporocarps (Epps \& Arnold 2010), for comensalistic interactions (Piazzon et al. 2011) for forest trees and their fungal pathogens (Vacher et al. 2008). This is considered a 
robust measure of network structure, less prone to biases derived from sampling effort and network size (Nielsen \& Bascompte 2007).

The diversity of ornamentals in nurseries and retail centers trading this category of plants is conjectural and generated by random processes from the perspective of community assembly rules. Therefore, testing analytical tools designed for the study of natural communities is interesting and insightful from theoretical and suggestive from practical point of view considering the control of alien species. The invasive process is favored in Europe by historical background: the invasion of new organisms originating from different geographic areas is favored by the lack of equilibrium within plant communities at higher latitudes characteristic for Europe, consequence of last glaciation (Wallace 1878) and enhanced by anthropogenic disturbances. The communities become permeable to invasive species as plants, animals but also pathogens, a property shaped by several other factors, such as global climatic change. Climate warming is acting on pathosystems favoring the emergence of new diseases based on the modifications suffered at the level of spatial distribution, temporal activity and community structure of pathogens to which must be added the effect of global trade with plants (Desprez-Lousteau et al. 2007).

The aim of the present study was to analyze the pattern of pathogen share among woody plant hosts using the analysis of the generated bipartite networks. The hosts were selected to cover the best sold ornamental woody species in North Western Transylvania to which was added a group of cultivated and native wild woody perennials sharing same pathogens' pool containing documented fungi, Oomycota, bacteria and phytoplasmas. We analyzed the emerging pathogen community structure using metrics devised for bipartite networks: degree distribution, connectance, nestedness and web asymmetry with additional information extracted from cluster analysis and niche overlap. Basically, we were interested whether from a relatively random assembly of hosts, a cohesive community of pathogens could arise. An important outcome would be the explanation of pathogenic spread and pathways for emerging and exotic pathogens in a new area by pathogen share among hosts.

\section{Material and methods}

\section{Study site and network sampling}

The geographical area of the study was located in Northwestern Transylvania, in urban environments: Oradea $\left(47^{\circ} 04^{\prime} 20^{\prime}\right.$ 'N; $\left.21^{\circ} 55^{\prime} 16^{\prime \prime} \mathrm{E}\right)$ and Cluj-Napoca (46 $45^{\prime} 58^{\prime \prime} \mathrm{N}$; 23 $\left.3^{\circ} 32^{\prime} 51^{\prime \prime} \mathrm{E}\right)$. Three gardening outlets, four flower shops were visited in Cluj-Napoca and two gardening outlets, two flower shops in Oradea for the evaluation of health state of the displayed woody species. Diseased material originating from Thuja plicata and Buxus sempervirens was obtained also from a nursery trading with ornamental species, in the proximity of Oradea. For the sake of confidentiality, the locations and names will not be disclosed.

The work hypothesis was constructed on the supposition of pathogenic spread from cultivated ornamental species intensively traded into the landscape, to other cultivated wild autochthonous species.

Field investigation developed in 2013 showed that imported material of Prunus laurocerasus displayed for sail contained diseased plants. The laboratory analysis showed that the lesions corresponded to the infection with an invasive new pathogen Xanthomonas arboricola pv. pruni Vauterin et al., an EPPO quarantine species (Tjou-Sin et al. 2012). Further investigation in gardening outlets and nurseries revealed on Buxus sempervirens frequent infections with Volutella buxi (DC.) Berk., Cyanonectria buxi (Fuckel)Schroers, Gräfenhan $\&$ Seifert and Cylindrocladium buxicola Henricot. On Thuja plicata were found infections with Pestalotiopsis funerea (Desm.) Steyaert, 
Passalora sequoiae (Ellis \& Everh.) Y.L. Guo \& W.H. Hsieh, Botryosphaeria spp., Macrophoma thujana Cooke \& Massee and Cercospora spp.

The number of inspected plants varied between 2 and 50 depending on the displayed number of pots in every location.

Three focal ornamental species were selected for network generation (subgraph) based on reported sales in shops and retail centers: Buxus sempervirens L. (European boxwood) is a shrub of Buxaceae family, Thuja plicata Donn ex D. Don (western redcedar of Pacific) of Cupressaceae family and Prunus laurocerasus L. (cherry laurel) of Rosaceae family, extensively used as ornamental species in Romania. A second extended network was based on list of pathogens (112 species) which was assembled using information from published papers, books and personal observations (supplemental information).

The compiled list contains true fungi, fungilike organisms (Oomycota), phytopathogenic bacteria and phytoplasma. From functional perspective, these organisms are classified as necrotrophic and biotrophic pathogens targeting different tissues and organs of the hosts (Garcia-Guzman \& Morales 2007). The list of pathogens contains also documented most important invasive species such as Phytophthora cinnamomi Rands, Phytophthora kernoviae Brasier, Beales \& S.A.Kirk, Phytophthora ramorum Werres, DeCock \& Mann in't Veld, Phytophthora lateralis Tucker \& Millbrath, Phytophthora citricola Sawada which are polyphagous species but also emerging / invasive oligophagous species such Pseudomonas syringae pv. morsprunorum Sawada, Takeuchi \& Matsuda, Candidatus phytoplasma prunorum Seemüller and Schneider, Peronospora sparsa Berk. on plants of Rosaceae family and Cylidrocladium buxicola Henricot. All of these species were reported for Europe and some of them for Romania. A number of generalist, autochthonous pathogens are included in the list such as Armillaria mellea s.l.(Vahl) P. Kum.,
Heterobasidion annosum (Fr.) Bref., Ganoderma applanatum (Pers.) Pat. or Verticillium dahliae Kleb. among others.

It is important to stress the fact that the listed hosts are not including all the host ranges of the pathogens but those species currently displayed for sale in gardening shops, economically important cultivated species and woody native species found in the investigated territory (species placed in phyla Coniferophyta and Magnoliophyta).

The host-pathogen network was assembled in two steps: first, to the woody ornamentals considered most abundant based on sale figures were attached documented and identified pathogens. Second step consisted in the attachment of documented hosts to the list of pathogens taking into account plants already present in retail centers, nurseries, urban areas and also woody native species from the investigated region. A presence-absence matrix resulted including 3 woody hosts and 112 pathogen species which was used to generate a bipartite network (Fig. 1). A second extended host - pathogen matrix contained 33 woody hosts and the same 112 pathogen species being used to generated a second bipartite network (Fig. 2).

\section{Network descriptors}

Degree distribution. A node's degree is the number of links directly established with other nodes in a network. The distribution of nodes' degrees represents an important network descriptor indicating the positional importance of nodes within the network (Vasas \& Jordán 2006). Ecological networks display scale free degree topology characterized by exponential, power law or truncated power law distributions (Jordano et al. 2003, Vásquez 2005). We performed the fitting of the observed degree distribution of the main network using maximum likelihood, calculating the coefficient of determination and Akaike Information Criterion (AIC) to select the best fit for exponen- 


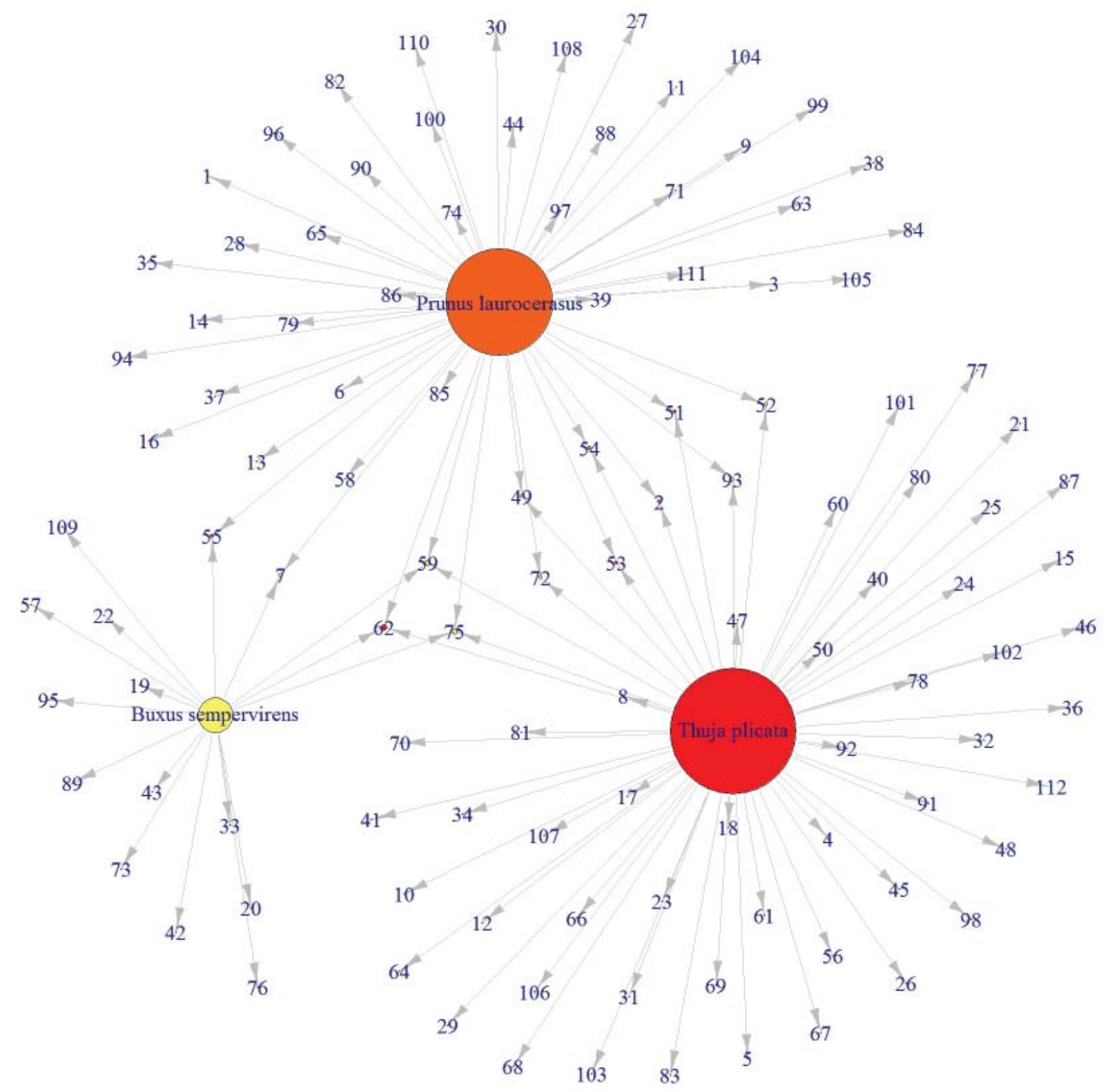

Figure 1 Bipartite network of 3 cultivated woody species (Thuja plicata, Buxus sempervirens and Prunus laurocerasus) and their associated pathogens (current numbers represent pathogen species listed below). Node size is correlated with the number of links

tial, truncated power law and power law distribution using $\mathrm{R}$ bipartite package version 2.03. Truncated power law was considered a better fit only if the difference AIC was greater than 2 (Blüthgen et al. 2008). The analysis was performed separately for plants (lower trophic level) and pathogens (higher trophic level). Due to the small number of hosts in the 3 woody species graph, the analysis of node degree distribution was not performed.
Connectance or connectivity $(C)$ is a global net index and quantifies the realized number of links per network also, the complexity of the web. In bipartite networks it is calculated as number of links divided by the number of matrix cells (number of higher trophic level nodes, in our case, pathogens and lower trophic level nodes, in our case, woody species) (May 1972, Dunne et al. 2002).

Web asymmetry $(W)$ evaluates the balance 


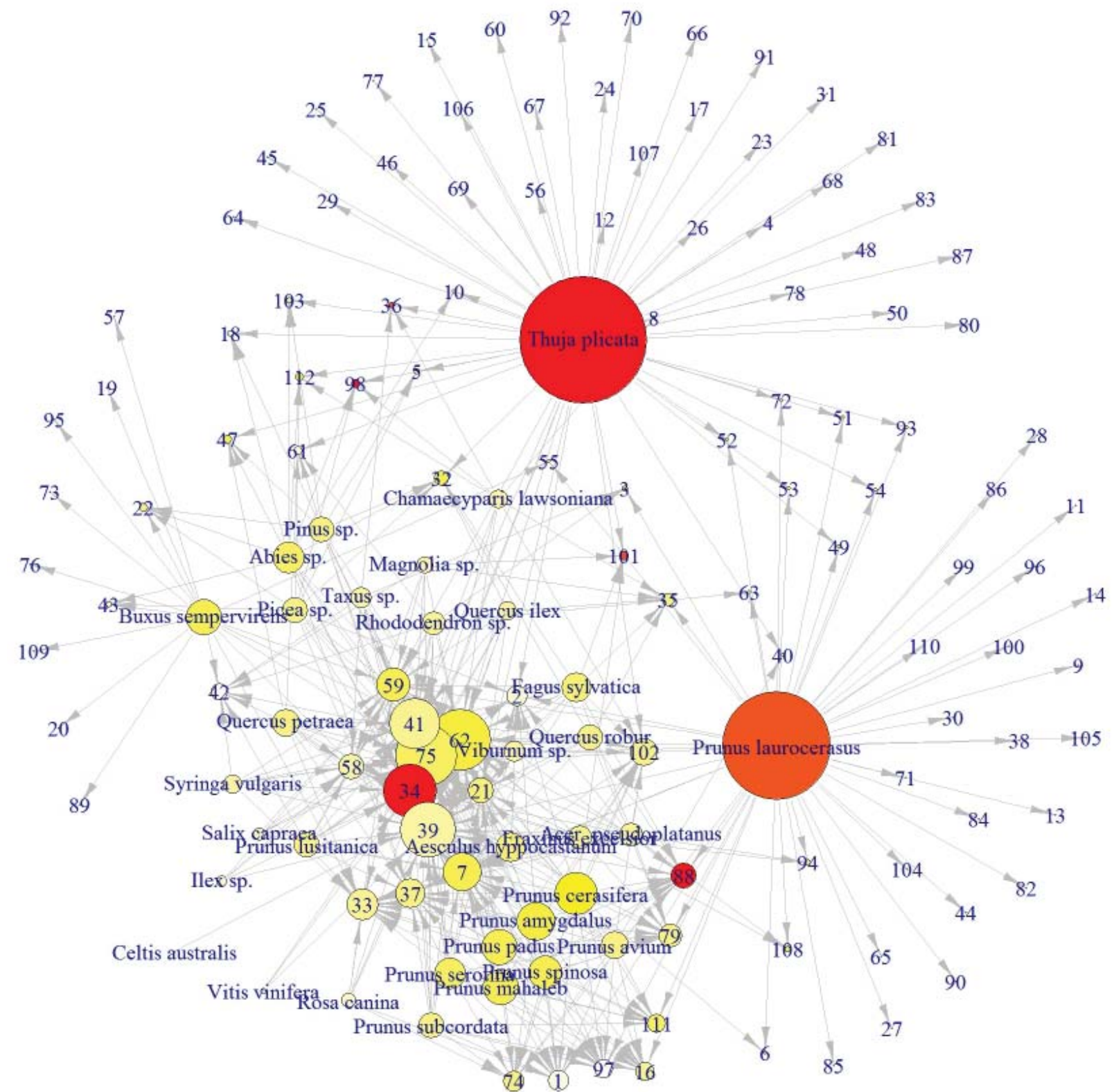

Figure 2 Bipartite network of 33 cultivated and wild woody perennials used in plant trade and their associated pathogens (current numbers represent pathogen species listed below). Node size is correlated with the number of links

Note. Pathogens list: 1. Agrobacterium tumefaciens, 2. Aleurodiscus occidentalis, 3. Aleurodiscus penicillatus, 4. Alternaria alternata, 5. Amylostereum chailletii, 6. Apiognomonia erythrostoma, 7. Armillaria mellea, 8. Armillaria ostoyae, 9. Blumeriella jaapi, 10. Botryosphaeria spp., 11. Candidatus phytoplasma prunorum, 12. Ceratocystis allantospora, 13. Ceratocystis angusticollis, 14. Cercospora circumscissa, 15. Cercospora spp., 16. Chondrostereum purpureum, 17. Colletotrichum gloeosporioides, 18. Coniophora olivacea, 19. Coniophora puteana, 20. Cyanonectria buxi, 21. Nectria cinnabarina, 22. Cytospora spp., 23. Datronia mollis, 24. Dermea balsamea, 25. Diaporthe lokoyae, 26. Didymascella thujina, 27. Diplodia phoradendri, 28. Diplodia seriata, 29. Euantennaria spp., 30. Eupropolella britanica, 31. Fabrella thujina, 32. Fomitopsis pinicola, 33. Cylindrocladium buxicola, 34. Fusarium commune, 35. Ganoderma applanatum, 36. Gibellula pulchra, 37. Heterobasidion annosum, 38. Hymenochaete tabacina, 39. Chloroscypha seaveri, 40. Lachnelulla spp., 41. Lepteutypa cupressi, 42. Macrophoma candollei, 43. Macrophoma thujana, 44. Meruliporia incrassata, 45. Monilinia spp., 46. Mycosphaerella spp., 47. Phytophthora citricola, 48. Phytophthora citrophthora, 49. Phytophthora kernoviae, 50. Phytophthora lateralis, 51. Phytophthora megasperma, 52. Phytophthora cambivora, 53. Phytophthora cryptogea, 54. Phytophthora drechsleri, 55. Phytophthora nicotianae, 56. Phytophthora parasitica, 57. Clonostachys buxi, 58. Peronospora sparsa, 59. Pestalotiopsis funerea, 60. Phacidium coniferarum, 61. Phaeolus schweinitzii, 62. Phanerochaete sanguinea, 63. Phellinus nigrolimitatus, 64. Phellinus ferreus, 65. Phellinus pini, 66. Phellinus weirii, 67. Phellinus punctatus, 68. Phoma spp., 69. Phomopsis stictica, 70. Phomopsis thujae, 71. Phyllactinia guttata, 72. Cladosporium spp., 73. Phytophthora ramorum, 74. Phytophthora cactorum, 75. Phytophthora cinnamomi, 76. 
Phytophthora syringae, 77. Phytopthora heveae, 78. Pleospora laricina, 79. Podosphaera pannosa, 80. Polyporus varius, 81. Postia balsamea, 82. Postia caesia, 83. Postia salmonicolor, 84. Postia stiptica, 85. Postia placenta, 86. Pseudomonas syringae pv. syringae, 87. Rosellinia buxi 88. Pseudomonas syringae pv. mors-prunorum, 89. Puccinia buxi, 90. Pythium helicoides, 91. Resinicium bicolor, 92. Rhizina undulata, 93. Schizophyllum commune, 94. Serpula lacrymans, 95. Sistotrema brinkmannii, 96. Sphaceloma spp., 97. Stereum sanguinolentum, 98. Stigmina carpophila, 99. Taphrina deformans, 100. Thielaviopsis basicola, 101. Trametes hirsutus, 102. Trametes versicolor, 103. Trichaptum abietinum, 104. Trichothecium roseum, 105. Trochila laurocerasi, 106. Valsa abietis, 107. Velutaria rufoolivacea, 108. Verticillium dahliae, 109. Volutella buxi, 110. Wilsonomyces carpophilus, 111. Xanthomonas arboricola pv. pruni, 112. Passalora sequoiae.

between the two levels of the bipartite graph (Blüthgen et al. 2007) calculated as the difference between higher level nodes minus lower level nodes divided by their sum. The index scales within the interval $[-1 ; 1]$. Positive numbers indicate higher trophic level species while negative numbers indicate lower trophic level species prevalence.

Network size $(M)$ was calculated as the product between number of lower trophic level nodes (woody species in our case) times higher trophic level nodes (pathogens, in our case).

Nestedness is a community univariate metric which illustrates a particular type of asymmetry in species interactions: considering both hosts and parasites specialized nodes/species are linked to more generalist nodes/species displaying many interactions calculated as $\mathrm{T}$ or the matrix temperature, a measure of how the presence/absence pattern departs from perfect nestedness (Bascompte et al. 2003, Vásquez et al. 2005). The basic idea behind nestedness calculation is to assess the state of ordering (Podani 2000, Ulrich \& Gotelli 2007). Nestedness is a non-dimensional index and is calculated as $N=(100-T) / 100$ for a matrix which contains pathogens on rows and hosts on columns: it was assessed using temperature calculator of Rodríguez-Gironés and Santamaría (2006) implemented in $\mathrm{R}$ package bipartite version 2.03 (Dormann et al. 2008) which finds the best minimum temperature matrix using a genetic algorithm. Values close to 1 indicate high degree of nestedness while values close to 0 indicate low nestedness.

Statistical validation was against the null matrices using r00 model in $\mathrm{R}$ package vegan version 2.0-10 (Oksanen et al. 2013). Null communities (Gotelli \& Graves 1996) are gen- erated in this manner and test statistic or index is calculated for each generated null community. Null model was considered to exclude the constrain of interest in community assemblage (Gotelli 2001), namely host-pathogen interaction which is not random in real world but specific. The interaction matrix was considered nested if the matrix temperature of the observed matrix was below or above the mean temperature of the 1000 simulated random matrices generated under the specified null model (Rodríguez-Gironés \& Santamaría 2006).

\section{Community descriptors}

Cluster analysis was performed using Euclidian metric and single linkage algorithm (cophenetic correlation $=0.96$ ), using $\mathrm{R}$ version 3.0.2 and included package stats (R Development Core Team 2013). Validation of cluster results used the internal measure calculated by Dunn index in R package clValid version 0.64 (Brock et al. 2011). Dunn index is the ratio between the smallest intra-cluster distance between observations not in the same cluster and the largest intra-cluster distance taking values between 0 and infinity and is recommended to be maximized.

Niche overlap (Colwell \& Futuyma 1971, Pianka 1974) being a symmetrical index was estimated to obtain a global descriptor for host sharing among specialist and generalist pathogens in other words, the joint resource utilizations by two or more species in addition to nestedness. The observed index was then compared to the average of 5000 indices obtained by simulation (null model selected: fixed row and fixed column). It was calculated using software EcoSim version 7.0 (Gotelli 
\& Entsminger 2004). The standardized effect size provided (SES, a z-transformed score) by the software was employed to assess the significance of results. SES values below -2.0 or above +2.0 indicate approximate statistical significance at 5\% error level (two-tailed test) and quantify the degree and the direction of deviation from the null model.

The graphical output for the analyzed metrics were generated in $\mathrm{R}$ package bipartite version 2.03 (Dormann et al. 2008) and the undirected bipartite networks were depicted in R package igraph version 0.7.0 (Csardi \& Nepusz 2006).

\section{Results}

The qualitative, undirected bipartite plantpathogen networks (Fig. 1 and Fig. 2) are illustrative for the intricate way of the established host-pathogen interactions: the simple spatial proximity provided by plant shops and retail centers is a sufficient condition to transfer pathogens among plants displayed for sale. Then, from managed landscapes to natural ecosystems, the pathway for introducing new pathogens is created.

For the sub-graph containing three focal woody species of hosts and for the main bipartite network, metrics are reported in Table 1. The bipartite graphs are depicted in Figures 1 and 2. The global network descriptor, connectance decreased proportionally with network size in our example: connectance within the smaller sub-graph (network size $=336$ ) containing only three hosts is larger than connectance within main network (network size $=$ 3696) containing 33 hosts and 112 pathogens. Buxus sempervirens accumulated 17 pathogen species which is equivalent to the corresponding node degree, Thuja plicata - 60 and Prunus lauroceraus - 51. A proportion of 59\% of the pathogens were specialists (attached to one host species, which was equivalent to node degree 1). The mean number of shared pathogens for main graph and subgraph is shown in Table 1 .

The remaining proportion of pathogens corresponded to oligophagous or polyphagous generalists (parasitizing within one genus to broad generalists attacking most of the hosts in the network). In sub-network containing three focal hosts, pathogens parasitizing only one host species were prevalent (89\%).

The degree distribution of the main network most closely resembled to truncated power law distribution for lower trophic level set of nodes (power exponent $=-0.45: \mathrm{R} 2=0.97: \mathrm{AIC}=$ -29.59 as compared to power law distribution fit with AIC = 3.12). For higher trophic level set represented by pathogens the best fit was power law distribution (power exponent $=$ 0.96: $\mathrm{R} 2=0.97: \mathrm{AIC}=-60.06$, and truncated power law distribution AIC = NA) (Fig. 4). The average density link was 3.06. For higher level set of nodes, few species displayed high number of links, most of the nodes being connected to few or only one host species, a situation encountered in other parasitic networks

Table 1 Network metrics and community descriptors calculated for the bipartite graph and subgraph of ornamental woody host species and their pathogens

\begin{tabular}{lcc}
\hline Network metrics & Subgraph & Main graph \\
\hline Number of nodes in the & 3 hosts, 112 & 33 hosts, 112 \\
Number of edges & 124.00 & 465.00 \\
Mean number of shared & 6.33 & 5.47 \\
Connectance & 0.38 & 0.12 \\
Web asymmetry & 0.94 & 0.54 \\
Network size & 336.00 & 3696.00 \\
Nestedness & $0.54 * * *$ & $0.94 * * *$ \\
\hline
\end{tabular}




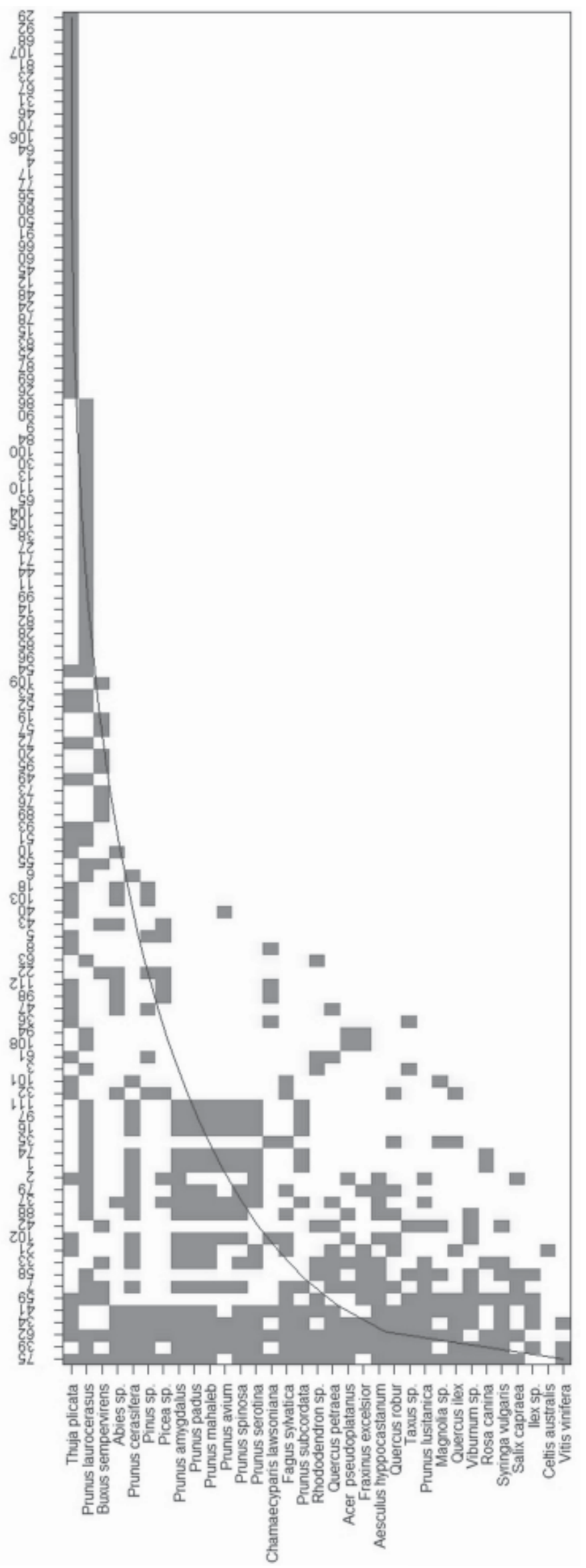

too (Griffith et al. 2014) and majority of mutualistic networks (Jordano et al. 2003). The pathogens linked with many hosts or generalist pathogens (more than 20 links) were: Fusarium commune, Chloroscypha seaveri, Lepteutypa cupressi, Phanerochaete sanguinea and Phytophthora cinnamomi. The next generalist species significant from epidemiological perspective linked with more than 10 hosts were: Armillaria mellea s.l., Cylindrocladium buxicola, Heterobasidion annosum, Pestalotiopsis funerea, Pseudomonas syringae pv. mors-prunorum, Xanthomonas arboricola pv. pruni and Peronospora sparsa. However, among specialized pathogens were placed important invasive species such as Phytophthora kernoviae, $P$. ramorum and $P$. lateralis.

The sub-graph containing three ornamental species was significantly less nested (0.54), with higher connectance (0.38) and higher web asymmetry (0.94). Both networks were characterized by the prevalence of higher trophic level species (pathogens).

In the extended network the relativelly low main network connectance $(0.12)$ corresponded to highly significant nestedness $(N=0.94)$. Statistical validation was based on 1000 simulated null matrices, hence the observed network was more nested than random simulations ( $p$ $<0.0009$ ). The packed matrix depicted in Figure 3 demonstrates the nested in

Figure 3 Matrix representation of the nested interaction pattern between 33 cultivated and wild woody perennials and their pathogens. Black squares correspond to links between hosts and pathogens; the curve represents the isocline corresponding to a perfectly nested matrix, the numbers correspond to the pathogens listed above 

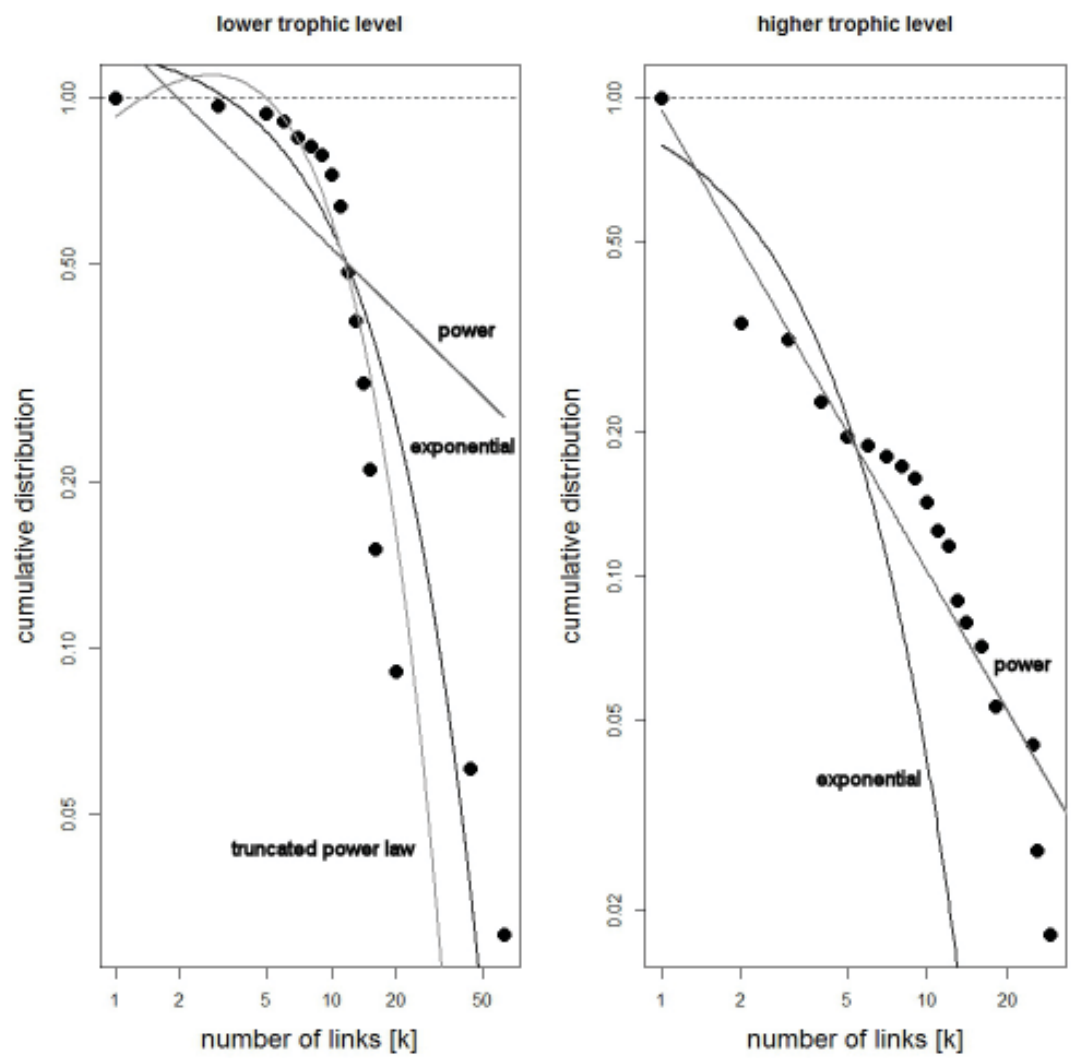

Figure 4 Cumulative degree distribution in host-pathogen interaction network (dots). Curves represents the expected distributions predicted by exponential, power low and truncated power low distributions (lower trophic level - plants, higher trophic level - pathogens)

teraction pattern among plants and pathogens.

Cluster analysis (Fig. 5) generated 6 main clusters based on resemblance in shared pathogens: Thuja plicata, Prunus laurocerasus and Buxus sempervirens clustered separately at relatively large distance from next three clusters merging the remaining thirty woody species. An intriguing result concerned the considered species of genus Prunus: P. laurocerasus established its own cluster at large distance from other woody species, P. lusitanica clustered with other angiosperms, in a different cluster from that in which other Prunus species merged. Both species contain high amounts of toxic cyanogenic glycosides, are evergreen shrubs and display a range covering the warmer climatic areas from Southern Europe, Asia Minor and North Africa (as Marocco for $P$. lusitanica).

Based on pathogen attachment as clustering criterion, the assemblage of hosts displayed high heterogeneity from biogeographical perspective being a mixture of autochthonous wild and cultivated species and exotics, ones frequently encountered in plant retail centers. Statistical validation using internal consistency criterion and Dunn test (value 1.81) showed that the selected hierarchical, single clustering algorithm combined with Euclidian distance resulted in significant partition of host species among clusters.

Niche overlap (Pianka 1974) calculated on the data from the main matrix showed significant partition of hosts among pathogens as expressed by the low value of the index ( 0.31 the observed mean of the index and 0.07 the mean of 5000 simulated indices at SES $=22.53$ ). Niche overlap can be assessed also through nestedness since in nested networks, the niche of all pathogens overlap with the niche of the 
more generalist ones (Poisot et al. 2013).

\section{Discussion}

Plant retail centers in Romania harbor collections of plants originating from different biogeographic regions and from different growers scattered over Europe sometimes for relatively long periods of time. The assembly of plants is dictated by economy and marketing, but from environmental perspective such a random gathering of organisms is never encountered in nature. We have established that the plant pathogens attached to this selection of hosts generate a structure which is increasingly nested and decreasingly connected with the addition of new hosts. The nested pattern is largely represented in nature and by its cohesiveness ensures the stability of interactions, especially with pathogenic networks which are rapidly evolving (Flores et al. 2011).

\section{Network metrics}

The analysis of node degree distribution revealed the position of each pathogen within the network, with important generalists among which species of Phytophthora are of special concern. The non-random nature of the net- work is important from epidemiological perspective because species characterized by high node degree among pathogens are of greater risk than more specialized species. However, not only a dominant position in a network is of concern when it comes to highly virulent, yet oligophagous pathogens. It was stressed elsewhere that small host-pathogen networks established within nurseries and outlets trading with diseased material can expand and represent a major threat from epidemiological perspective (Pautasso et al. 2010). On the other hand, the frequency of species interactions emerges from species traits (Vásquez 2005), both hosts and their pathogens but also from the ability of pathogens to acquire new hosts. The network growth by attaching new hosts obeyed to the rule of preferential attachment with regard to pathogens (Barabasi \& Albert 1999) being determined by the particular nature of host-pathogen interaction as an interplay between susceptibility and virulence. The node degree distributions were fitted by different theoretical models for hosts and pathogens, a noteworthy characteristic of the described main network.

Our results revealed that the network metrics (connectivity, web asymmetry, nestedness) of main interaction graph and of three hosts subgraph in our survey scaled with network size,

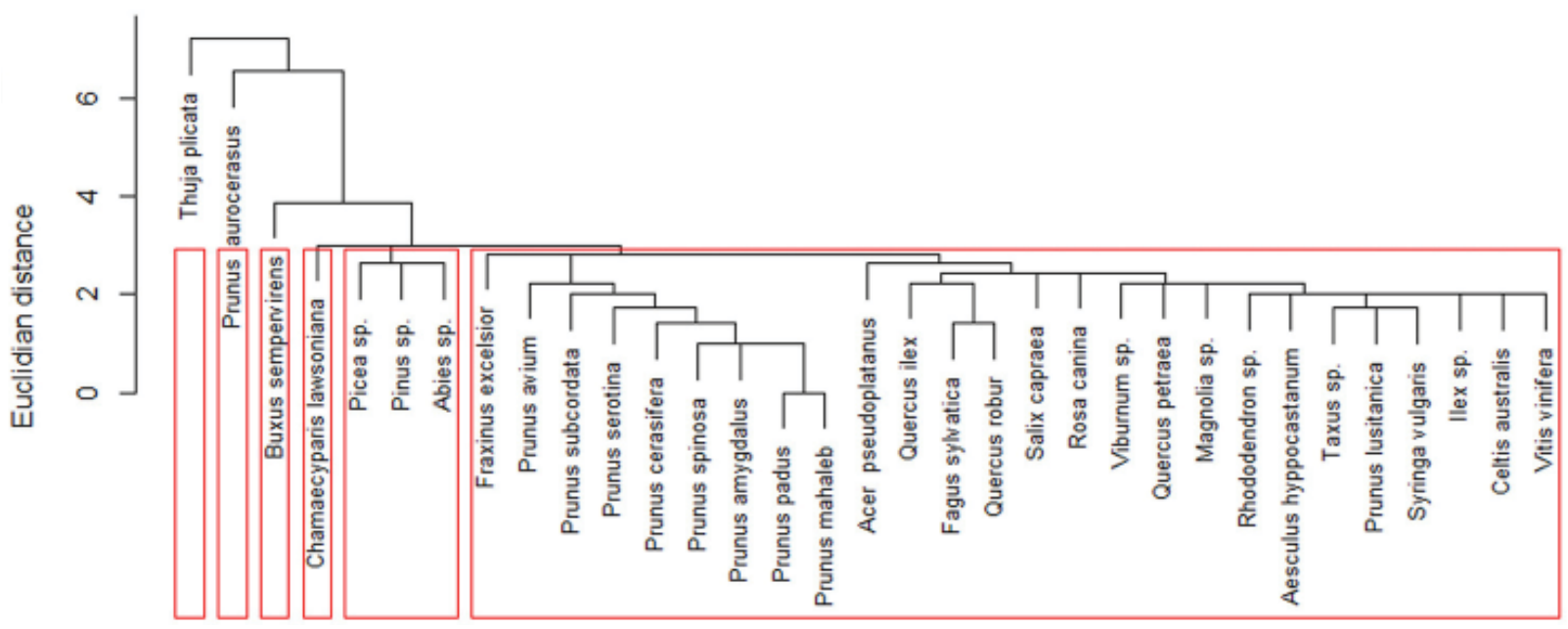

Figure 5 Dendrogram depicting the distances in terms of shared pathogens among 33 cultivated and wild woody perennials (Euclidian distance). The clusters are framed in red 
high nestedness emerging as a property of the larger web: scaling property of the networks was demonstrated previously with trophic webs (Dunne at al. 2013). It is considered that this property emerges in large networks (over 150 nodes) being dependent on high representation of generalist consumers/pathogens and increasing diversity of specialized consumers/ pathogens (Montoya et al. 2006).

It is expected that pathogens establishing communities on these more abundantly represented species are more likely to escape to other plant species as potential hosts in managed areas or into the natural ecosystems. The supposition is based on already demonstrated hypothesis of correlation between abundant hosts and diverse pathogen assemblies linked to these hosts (Váquez et al. 2005).

The sub-graph depicting the assemblage of pathogen community on three ornamental species largely distributed within the territory by anthropogenic intervention displayed structure with different traits illustrated by the employed network metrics: high connectance, low nestedness and high web asymmetry.

As global network descriptor, nestedness in bipartite antagonistic networks is correlated with web size and species richness (Graham et al. 2009). Nestedness indicates that specialized pathogens interact with generalist hosts which harbor a complex community of generalist as well as specialist pathogens. This pattern is common to many other antagonistic networks previously described (Poulin 1997, Vásquez et al. 2005, Vacher et al. 2008, Graham et al. 2009).

The emergence of nested pattern in large pathogen communities is the expected outcome of gene-to-gene interaction (Agrawal \& Lively 2002), of the differential host ranges or specialization of pathogens largely being classified as specialists and generalists; specialists will attach to a restricted range of taxonomically close host species being consequently subsets of larger set of hosts shared by generalist pathogens (Graham et al. 2009, Bascompte et al. 2003, Guimarães et al. 2006). Hosts with high resemblance in pathogen communities are expected to exchange pathogens given a convenient pathway, the case of Prunus laurocerasus harboring a highly virulent invasive pathogen such as Xanthomonas arboricola pv. pruni and other cultivated and wild species of genus Prunus. An important observation on the prevalence of specialists among pathogens can be linked to the fact that it was previously stated that specialists interact preferentially with most abundant hosts (Vacher et al. 2008). In particular, the way nestedness emerges in pathogenic networks is dependent on whether a new species enters the community leading to nestedness due to the fact that it minimizes the competitive load by targeting generalist hosts (Bastolla et al. 2009), as in the case of Phytophthora spp. It is highly probable that the specialization asymmetry which leads to network asymmetry and nestedness is the consequence of such important disease attributes as host susceptibility and pathogen virulence developed in the frame of co-evolution.

The network representations of the pathogenic interactions emphasizes the importance of connectivity (Fenner et al. 2011) which is responsible for pathogen spread within the compatible hosts range. Connectivity is responsible at local scale for pathogen transmission from highly connected hosts. One important consequence of network topology is the openness of pathogen-host interaction networks in the sense of possible attachment of hosts and pathogens to a preexisting web as new contributors to connectivity, creating pathways to the emergence of new pathosystems. It proves that bipartite networks are building blocks of more complex ecological networks (Kondoh et al. 2010). In the analyzed host-pathogen networks, the previous observation made on comensalistic networks showing a parallel increase of connectivity, nestedness with network size (Piazzon et al. 2011) was not confirmed. The observed pattern at the two scales (main network and the three hosts subnetwork) 
showed a decrease of connectivity paralleling emergence of high nestedness and increase of the network size, similar with the situation described for plant-pollinator networks (Memmott 1999). However, the correlation between network size and connectivity is a controversial issue; there are opinions that these two network descriptors are in fact, un-correlated (Flores et al. 2011).

The interactions within the described network are asymmetric, a characteristic recognized by various researchers of parasitic and mutualistic networks, due to the fact that links are achieved only with compatible hosts in terms of disease attributes or mutualistic specialization (Jordano et al. 2006). This specificity of links is determined by molecular recognition mechanisms in order to avoid hosts' defense mechanisms, a property shared with other documented antagonistic networks including galling and leaf-mining insects and parasites (Hespenheide 1991, Harris et al. 2003, Sachs et al. 2011).

It was stated that networks displaying low connectivity and high diversity/number of nodes are more exposed to invasion by pathogens or other types of consumers (Romanuk et al. 2009). We simulated network increase by adding new host species which led to the concentration of specialist pathogens within same cluster of the network. The re-arranged matrix for nestedness search showed a considerable number of specialized pathogens which represented $59 \%$ of species within the assembly whereas in three species sub-graph this proportion reached $89 \%$. This empirical fact shows a trend in generalist species accumulation with network increase and in a lesser extent the addition of new specialists.

\section{Community analysis}

Cluster analysis confirmed the emergence of the pattern in pathogen community attached to a random selection of diverse assembly of hosts from taxonomic and biogeographic per- spective. The separation of distinct clusters is the consequence of pathogens targeting their specific, susceptible hosts as a result of coevolution demonstrating that pathogens attack under the control of specific disease attributes. Similar clusters were highlighted in larger assemblies of trees, 51 taxa and their pathogens, 157 taxa (Vacher et al. 2008) as proof of nonrandom assembly of host species according to phylogeny and co-evolution with their pathogens.

The genus Prunus spp. harbors important commercial, large scale cultivated species and establish their own cluster in terms of shared pathogens. Prunus laurocerasus cluster separately while others Prunus species are clustering together as members of bigger clusters with Fraxinus excelsior and Chamaecyparis lawsoniana among others. Prunus lusitanica clusters together with the Fagus sylvatica, Quercus robur, Aesculus hippocastanus in a different cluster. These two species of Prunus are characterized by high levels of toxigenic glycosides being also thermophiles, features which differentiate them from other species within the genus. It is also more likely that hosts will exchange pathogens more often within their own cluster however; pathogens jumping between clusters are frequently encountered and are generalists or invasive species. Xanthomonas arboricola pv. pruni is infecting cultivated Prunus such as $P$. cerasifera, $P$. avium but also $P$. laurocerasus and $P$. lusitanica which are clustering differently.

Among angiosperms, Quercus robur and $\mathrm{Fa}$ gus sylvatica clustered closely, a similar result being obtained in other studies developed on networks established by trees and pathogens (Vacher et al. 2008). The important genera Pinus, Abies and Picea clustered together, while Thuja plicata, also a coniferous species established its own cluster.

Niche overlap as Pianka stated (1974) sheds light on the way species partition available resources (in our case, how pathogens share a pool of hosts), the partition being a determi- 
nant of species diversity. The information gain brought by niche overlap index concerns the mechanism of community assembly in which resource utilization is partitioned among pathogens with minor competition involved due to the small overlap in host utilization, creating the grounds for a continuous increase of pathogens' diversity. Nestedness and niche overlap are in fact the two sides of the same coin: specialist pathogens are using same host species with generalists being subsets of the larger pathogens assortment in other words. For specialists which are the majority, niche breadth is narrow and overlap areas are small.

\section{Conclusions}

Starting with a random assembly of hosts containing cultivated and wild species/ autochthonous and exotic species, our study demonstrated that an organized network emerged by sharing a common pool of pathogens. The structural properties varied with the size of the network.

Network metrics scaled with network size excepting nodes' degree distribution (a scale free property). Hosts and pathogens displayed differences in what concerned the node degree distribution (truncated power law fitted the hosts node degree distribution while power law was a better fit for pathogens' node degree distribution).

Nestedness scaled with network size, with the large network being more nested. The nestedness in pathogenic networks is an outcome of gene-for-gene interaction with smaller subsets of the graph containing specialized pathogens included in the generalists' subsets.

Connectivity decreased with network size and the interactions were asymmetric due to differences in specialization.

Clustering showed the differentiation of distinct groups of hosts according to shared pathogens. Thuja plicata, Buxus sempervirens and Prunus laurocerasus were clustering sepa- rately.

Niche overlap and nestedness reflected same important property in different ways: most of the pathogens occupied a narrow range of resources in terms of shared hosts and few could use a wide range of resources/hosts. The different pattern in resource utilization generated the nested assembly of pathogen community with respect to a random selection of hosts.

Most important pathogens from epidemiological perspective highlighted by the network analysis were: Cylindrocladium buxicola, Phytophthora kernoviae, P. lateralis, P. cinnamomi, $P$. ramorum, Pseudomonas syringae pv. mors-prunorum, Xanthomonas arboricola pv. pruni and Pestalotiopsis funerea.

Network analysis can improve our projections on alien pathogens fate in new environments and contribute to the knowledge of pathogen communities and the ways they assembly. The present study was performed for the first time in Romania with the explicit aim of describing host-pathogen interaction in the context of the invasive spread of diseases triggered by trade globalization.

\section{References}

Agrawal A.F., Lively C.M., 2002. Infection genetics: Genefor-gene versus matching allele models and all points in between. Evolutionary Ecology Research 4: 79-90.

Almeida-Neto M., Guimarães Jr. P.R., Lewinsohn T.M., 2007. On nestedness analyses: rethinking matrix temperature and anti-nestedness. Oikos 116: 716-722. DOI: 10.1111/j.0030-1299.2007.15803.x.

Atmar W., Patterson B.D., 1993. The measure of order and disorder in the distribution of species in fragmented habitat. Oecologia 96: 373-382. DOI: 10.1007/ BF00317508.

Barabási R., Albert R., 1999. Emergence of scaling in random networks. Science 286: 509-512. DOI: 10.1126/ science.286.5439.509.

Bascompte J., Jordano P., Melian C.J., Olesen J.M., 2003. The nested assembly of plant-animal mutualistic networks. PNAS 100: 9383-9387. DOI: 10.1073/ pnas. 1633576100 .

Bastolla U., Fortuna M.A., Pascual-Garcìa A., Ferrera A., Luque B., Bascompte J., 2009. The architecture of mutualistic networks minimizes competition and increases biodiversity. Nature 458: 1018-1020. DOI: 10.1038/na- 
ture07950.

Blüthgen F., Menzel F., Hoverstadt T., Fiala B., Blüthgen N., 2007. Specialization, constraints and conflicting interests in mutualistic networks. Current Biology 17: 341-346. DOI: 10.1016/j.cub.2006.12.039.

Blüthgen N., Fründ J., Vásquez D.P., Menzel F., 2008. What do specialization network metrics tell us about specialization and biological traits? Ecology 89(2): 3387-3399. DOI: 10.1890/07-2121.1.

Borer E., 2013. Plant sharing pathogens: a recipe for successful invasion. S 2.4. in: Plant interactions with other organisms; molecules, ecology and evolution. $32^{\text {rd }} \mathrm{New}$ Phytologist Symposium. Universidad Católica Argentina, Buenos Aires 20-22 November.

Brock G., Pihur V., Datta S., Datta S., 2011. clValid: Validation of Clustering Results. R package version 0.6-4. http://CRAN.R-project.org/package $=$ clValid.

Burns K.C., 2007. Network properties of an epiphyte metacommunity. Journal of Ecology 95(5): 1142-1151. DOI: $10.1111 /$ j.1365-2745.2007.01267.x.

Colwell R.K., Futuyma D.J., 1971. On the measurement of niche breadth and overlap. Ecology 52(4): 567-576. DOI: $10.2307 / 1934144$.

Csardi G. Nepusz T., 2006. The igraph software package for complex network research, InterJournal, Complex Systems 1695. http://igraph.org.

Dale M.R.T., Fortin M.J., 2010. From graphs to spatial graphs. Annual Review of Ecology, Evolution and Systematics 42: 21-38. DOI: 10.1146/annurev-ecolsys102209-144718.

Desprez-Lousteau M.L., Robin C., Buee M., Courtecuisse R., Garbaye J., Suffert F., Sache I., Rizzo D.M., 2007. The fungal dimension of biological invasions. Trends in Ecology and Evolution 22: 472-480. DOI: 10.1016/ j.tree.2007.04.005.

Dormann C.F., Gruber B., Fruend J., 2008. Introducing the bipartite Package: Analysing Ecological Networks. R news Vol 8/2,8 - 11.

Dunne J.A., Lafferty K.D., Dobson A.P., Hechinger R.F., Kuris A.M. et al., 2013. Parasites Affect Food Web Structure Primarily through Increased Diversity and Complexity. PLOS Biology 11(6): e1001579. DOI: 10.1371/journal.pbio.1001579.

Dunne J.A., Williams R.J., Martinez N.D., 2002. Network structure and biodiversity loss in food webs: robustness increases with connectance. Ecology Letters 5:558-567. DOI: 10.1046/j.1461-0248.2002.00354.x.

Epps M.J., Arnold A.E., 2010. Diversity, abundance and community network structure in sporocarp associated beetle communities in Appalachian Mountains. Mycologia 102(4): 785-802. DOI: 10.3852/09-161.

Fenner A.L., Godfrey S.S., Bull M.C., 2011. Using social networks to deduce whether residents or dispersers spread parasites in a lizard population. Journal of Animal Ecology 80: 835-843. DOI: 10.1111/j.13652656.2011.01825.x.

Flores C.O., Meyer J.R., Valverde S., Farr L., Weitz J.S., 2011. Statistical structure of host-phage interaction. PNAS 108(28): E288-E297. DOI: 10.1073/ pnas. 1101595108

Garcia-Guzman G., Morales E., 2007. Life-history of plant pathogens. Distribution patterns and phylogenetic analysis. Ecology 88: 589-596. DOI: 10.1890/05-1174.

Gotelli N.J., 2001. Research frontiers in null model analysis. Global Ecology and Biogeography 10(4): 337-343. DOI: $10.1046 /$ j.1466-822X.2001.00249.x.

Gotelli N.J., Entsminger G.L., 2004. EcoSim: Null models software for ecology. Version 7.0. Acquired Intelligence Inc. \& Kesey-Bear. Jericho, VT 05465. Available online at: http://garyentsminger.com/ecosim/index.htm.

Gotelli N.J., Graves G.R., 1996. Null models in ecology. Smithsonian Institution Press, Washington, D.C., U.S A.

Graham S.P., Hassan H.K., Burkett-Cadena N.D., Guyer C., Unnasch T.R., 2009. Nestedness of ectoparasite-vertebrate host networks. PLOS ONE 4(1): e7873. DOI: 10.1371/journal.pone.0007873.

Griffith E.C., Pedersen A.B., Fenton A., Petchey O.L., 2014. Analysis of a summary network of co-infection in humans reveals that parasites interact most via shared resources. Proceedings of the Royal Society B. 281: 20132286. DOI: 10.1098/rspb.2013.2286.

Guimarães P.R. Jr., Sazima C., Furtado dos Reis S., Sazima I., 2006. The nested structure of marine cleaning symbioses: is it like fl owers and bees? Biology Letters 3(1): 51-54. DOI: 10.1098/rsbl.2006.0562.

Hall G., Cook R.T.H., Bradshaw W.J., 1992. First record of Peronospora sparsa on Prunus laurocerasus. Plant Pathology 4(2): 224/227.

Harris M.O., Stuart J.J., Mohan M., Nair S., Lamb R.J., Rohfritsch O., 2003. Grasses and gall midges: plant defense and insect adaptation. Annual Review of Entomology 48: 549-577. DOI: 10.1146/annurev. ento.48.091801.112559.

Hespenheide H.A., 1991. Bionomics of leaf-mining insects. Annual Review of Entomology 36: 535-560. DOI: 10.1146/annurev.en.36.010191.002535.

Jordano P., Bascompte J., Olesen J.M., 2003. Invariant properties in co-evolutionary networks of plant-animal interactions. Ecology Letters 6: 69-81. DOI: 10.1046/ j.1461-0248.2003.00403.x.

Jordano P., Bascompte J., Olesen J.M., 2006. The ecological consequences of complex topology and nested structure in pollination webs. In: Waser NM, Ollerton J (Eds.), Plant-Pollinator Interactions: From specialization to Generalization. University Presses Marketing, Bristol, (Chapter 8): 173-199.

Keller R.P., Geist J., Jeschke J.M., Kühn I., 2011. Invasive species in Europe: ecology, status and policy. Environmental Sciences Europe 23:23. DOI: 10.1186/21904715-23-23.

Kondoh M., Kato S., Sakato Y., 2010. Food webs are built up with nested subwebs. Ecology 91: 3123-3130. DOI: 10.1890/09-2219.1.

La Porta N., Capretti P., Thomsen I.M., Kasanene R., Hietala A.M., von Weissenberg K., 2008. Forest pathogens with higher damage potential due to climate change in Europe. Canadian Journal of Plant Pathology 30: 177 - 
195. DOI: 10.1080/07060661.2008.10540534.

Lafferty K.D., Dobson A.P., Kuris A.M., 2006. Parasites dominate food web links. PNAS 103 (3): 11311-11216.

May R.M., 1972. Stability and complexity in model ecosystems. Princeton University Press. 292 pp.

Memmott J., 1999. The structure of a plant-pollinator food web. Ecology Letters 2: 276-280. DOI: 10.1046/j.14610248.1999.00087.x.

Montoya J.M., Pimm S.L., Solé R.V., 2006. Ecological networks and their fragility. Nature 442: 259-264. DOI: 10.1038/nature04927.

Nielsen A., Bascompte J., 2007. Ecological networks nestedness and sampling effort. Journal of Ecology 95: 1134-1141. DOI: 10.1111/j.1365-2745.2007.01271.x.

Oksanen J., Blanchet F.G., Kindt R., Legendre P., Peter R., Minchin R., O’Hara B., Simpson G.L., Solymos P., Henry M., Stevens H., Wagner H., 2013. vegan: Community Ecology Package. R package version 2.0-10. http://CRAN.R-project.org/package=vegan.

Pautasso M., Moslonka-Lefebvre M., Jeger M.J., 2010. The number of links to and from the starting node as a predictor of epidemic size in small-size directed networks. Ecological Complexity 7: 424-432. DOI: 10.1016/j.ecocom.2009.10.003.

Pianka E.R., 1974. Niche overlap and diffuse competition. PNAS 71(5): 2141-2145. DOI: 10.1073/ pnas.71.5.2141.

Piazzon M., Larrinaga A.R., Santamaria L., 2011. Are nested networks more robust to disturbance? A test using epiphyte-tree commensalistic networks. PLOS ONE 6(5); e19637. DOI: 10.1371/journal.pone.0019637.

Podani J., 2000. Introduction to the exploration of multivariate biological data. Backhuys Publishers, Leiden, The Netherlands. 407 pp.

Poisot T., Stanko M., Miklisova D., Morand S., 2013. Facultative and obligate parasite communities exhibit different network properties. Parasitology 140(11): $1340 / 1345$.

Poulin R., 1997. Parasite faunas of freshwater fish: the relationship between richness and the specificity of parasites. International Journal for Parasitology 27(9): 1091-1098. DOI: 10.1016/S0020-7519(97)00070-2.

Poulin R., 2010. Network analysis shining light on parasite ecology and diversity. Trends in Parasitology 26(10): 492-498. DOI: 10.1016/j.pt.2010.05.008.

R Development Core Team, 2013. R: A language and environment for statistical computing. R Foundation for Statistical Computing, Vienna, Austria. URL http://www. R-project.org/.

Rodríguez-Gironés M.A., Santamaría L., 2006. A new algorithm to calculate the nestedness temperature of presence-absence matrices. Journal of Biogeography 33: 924-935. DOI: 10.1111/j.1365-2699.2006.01444.x.

Romanuk T.N., Zhou Y., Brose U., Berlow E.L., Williams R.D., Martinez N.D., 2009. Predicting invasion success in complex ecological networks. Philosophical Transactions of the Royal Society B 364: 1743-1754. DOI: 10.1098/rstb.2008.0286.
Sachs J.L., Essenberg C.J., Turcotte M.M., 2011. New paradigms for the evolution of beneficial infections. Trends in Ecology \& Evolution 26: 202-209. DOI: 10.1016/ j.tree.2011.01.010.

Santini A., Ghelardini L., De Pace C., Desprez-Loustau M.L., Capretti P., Chandelier A., Cech T., Chira D., Diamandis S., Gaitniekis T. et al. 2013. Biogeographical patterns and determinants of invasion by forest pathogens in Europe. New Phytologist. 197: 238-250. DOI: 10.1111/j.1469-8137.2012.04364.x.

Thompson J.N., 1994. The coevolutionary process. University of ChicagoPress, Chicago. 383 pp. DOI: 10.7208/ chicago/9780226797670.001.0001.

Tjou-Sin N.N.A., van de Bilt J.L.J., Bergsma-Vlami M., 2012. First report of Xanthomonas arboricola pv. pruni in ornamental Prunus laurocerasus. Plant Disease 96(5): 779.

Ulrich W., Gotelli N.J., 2007. Null model analysis of species nestedness patterns. Ecology 88: 1824-1831. DOI: 10.1890/06-1208.1.

Vacher C., Piou D., Desprez-Loustau M.L., 2008. Architecture of an Antagonistic Tree/Fungus Network: The Asymmetric Influence of Past Evolutionary History. PLOS ONE 3(3): e1740. DOI: 10.1371/journal. pone. 0001740.

Vasas V., Jordán F., 2006. Topological keystone species in ecological interaction networks: Considering link quality and non-trophic effects. Ecological Modelling 25(34): 365-378. DOI: 10.1016/j.ecolmodel.2006.02.024.

Vásquez D.P., 2005. Degree distribution in plant-animal mutualistic networks: forbidden links or random interactions? Oikos 108(2): 421- 426. DOI: 10.1111/j.00301299.2005.13619.x

Vásquez D.P., Poulin R., Krasnov B.R., Shenbrot G.I., 2005. Species abundance patterns and the distribution of specialization in host-parasite interaction networks. Journal of Animal Ecology 7(5): 946-955. DOI: 10.1111/j.1365-2656.2005.00992.x.

Wallace A.R., 1878. Tropical Nature, and Other Essays. Macmillan \& Co., London and New York. i-(xvi), 1-356 pp.

Williams R.J., 2011. Biology, Methodology or Chance? The Degree Distributions of Bipartite Ecological Networks. PLOS ONE 6(3): e17645. DOI: 10.1371/journal. pone. 0017645 .

\section{Supporting Information}

The online version of the article includes the Supp. Info.

Table 1. Pathogens and hosts presented in the bipartite network - references 